\title{
The value of intra-operative MRI in trans-sphenoidal pituitary surgery
}

\author{
Michael Powell
}

Received: 22 March 2011 / Accepted: 23 March 2011 /Published online: 27 April 2011

(C) Springer-Verlag 2011

Intra-operative MRI (iMRI) promises neurosurgeons a great deal, and far from being a research tool, as it was in the late 1990s, there are now a number of neurosurgical units throughout the world with this facility; more than 12 in Europe alone and many more in North America. It is finding many uses, perhaps most valuably in the resection of intrinsic brain tumours. At the time of commissioning of the iMRI in this author's unit in 2010, approximately $40 \%$ of the use of the machine was expected-like elsewhere in Europe - to be for the resection of pituitary adenomas.

It had always been a particularly attractive option for pituitary surgeons, as it offers us the possibility of finding out where, at the end of a trans-sphenoidal resection, residual tumour lies, long before the review MRI at some point after the end of the operative procedure. All those who manage these tumours on a regular basis, know that the early post-operative scan done in the following days can be disappointing and frustrating [2], and this reviewer had personally followed the advice given some 25 years ago by a world leader in the field to avoid doing this whenever possible - as it usually is, except when unforeseen post-operative events occur.

Many of us were strongly influenced by the papers from the University of Erlangen [4], where the fortunate conjunction of Siemens MRI scanning development occurred as well as being the then home of the unit of one of the most prolific pituitary neurosurgical units in Europe. As a consequence, we have seen a number of papers which set out the benefits in pituitary surgery. However, in practice when we had our own machines, not all of us were so convinced that the extra time (in my own unit more than doubling the operative

\section{Powell $(\bowtie)$}

The National Hospital for Neurology and Neurosurgery,

Queen Square,

London WC1N 3BG UK

e-mail: michael.powell@uclh.nhs.uk time for a single scan) taken in obtaining an iMRI was, perhaps, as beneficial as the neurosurgeons in Erlangen had suggested. Most papers show that the completeness of resection rises by about $20 \%$.

The disappointment stems from the knowledge that in awkwardly shaped tumours, most know where the residual tumour will lie, and have expected intra-operative difficulties in achieving complete resection. All the iMRI shows is just that, and that total tumour removal can remain frustratingly unachievable.

We have, of course, other options. A Seattle group [1] have reported the benefits of the quicker intra-operative CT scanner, and others have questioned whether endoscopy could do away with the need for iMRI at all [5].

There can be no doubt that 'complete' or very near complete resection of pituitary adenomas significantly reduces the chance of recurrence (unpublished data), so any method has at least theoretical major advantages. We have all to accept that the trans-sphenoidal route will not get tumour out of the cavernous sinus, except in exceptional circumstances, and the value of pursuing such a benign tumour into this surgically tricky area has long been debated. It is usually better to leave this area to radiation.

For the comparative novice, the secondary use of iMRI is as image guidance. As many have pointed out, experience reduces complications, and losing one's way in the approach to the pituitary fossa is the single most potent cause of these complications. However, the iMRI suites were not really a solution to these technical approach difficulties, because of the time penalty.

In this issue, Ramm-Pettersen et al. [3] propose the use of the low-field, mobile iMRI scanner. This is of interest as the number of units employing these devices is unknown, but far exceeds the vastly more expensive iMRI suite. It has always been thought that the image quality would be of lesser use, but perhaps this is not the case as the image quality is fine. 
These authors conclude that it does not add significantly to the operation time - clearly a major advantage - and that it has significant advantages in low number units, with relative inexperience in the technique. Any such advantage may be worth a look for those in this position. No doubt we shall see.

\section{Conflicts of interest None.}

\section{References}

1. Eboli P, Shafa B, Mayberg M (2011) Intraoperative computed tomography registration and electromagnetic navigation for transsphenoidal pituitary surgery: Accuracy and time effectiveness. J Neurosurg 114:329-335
2. Kremer P, Forsting M, Ranaei G, Wuester C, Hamer J, Sartor K, Kunze (2002) Magnetic resonance Imaging after transsphenoidal surgery of clinically non functioning pituitary macroadenomas and it $\mathrm{s}$ impact on detecting residual adenoma. Acta Neurochir 144:433-443

3. Ramm-Pettersen J, Berg-Johnsen J, Hol PK, Roy S, Bollerslev J, Schreiner T, Helseth E (2011) Intraoperative MRI facilitates tumour resection during transsphenoidal surgery for pituitary adenomas. Acta Neurochir. doi:10.1007/s00701-011-1004-7

4. Steinmeier R, Fahlbusch R, Ganslandt O, Nimsky C, Buchfelder M, Kaus M, Heigl T, Lenz G, Kuth R, Huk W (1998) Intraopertaive magnetic resonance imaging with the magnetom open scanner: concepts, neurosurgical indications and procedures: a preliminary report. Neurosurgery 43:739-747

5. Theodosopoulos PV, Leach J, Kerr RG, Zimmer LA, Denny AM, Guthikonda B, Froelich S, Tew JM (2010) Maximising the extent of resection during transspenoidal surgery for pituitary adenoma: can endoscopy replace intraoperative magnetic resonance imaging? J Neurosurg 112:736-743 